\title{
The struggling urology trainee: A qualitative study into causes of underperformance.
}

\begin{tabular}{|c|c|}
\hline Journal: & ANZ Journal of Surgery \\
\hline Manuscript ID & ANS-2019-01303.R1 \\
\hline Manuscript Type: & Original Article \\
\hline $\begin{array}{r}\text { Date Submitted by the } \\
\text { Author: }\end{array}$ & 23-Feb-2020 \\
\hline Complete List of Authors: & $\begin{array}{l}\text { McLeod, Kathryn; Barwon Health, Department of Urological Surgery; } \\
\text { Deakin University School of Medicine, Department of Surgery } \\
\text { Waller, Susan; Latrobe Regional Hospital, Department of Rural Health } \\
\text { King, Dennis; Alfred Health, Department of Surgery } \\
\text { Nestel, Debra; The University of Melbourne, Department of Surgery }\end{array}$ \\
\hline General Key Words: & Urology, Surgical Education \\
\hline Specialty Key Words: & performance, causes, qualitative research, resident, specialist training, \\
\hline
\end{tabular}


Title page

The struggling urology trainee: A qualitative study into causes of underperformance.

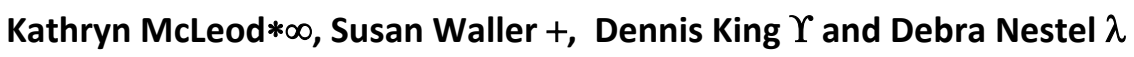

*Department of Urological Surgery, Barwon Health, University Hospital, Victoria, Australia.

$\Upsilon$ Department of Surgery, Alfred Hospital, Prahran, VIC, Australia.

$\infty$ Department of Surgery, Deakin University, Geelong, Victoria, Australia.

+ Monash University Department of Rural Health, Latrobe Regional Hospital, Traralgon, VIC, Australia.

$\lambda$ Department of Surgery, University of Melbourne, Heidelberg, VIC, Australia.

K. McLeod MBBS, FRACS (Urol.); D.King BHB, MBChB, FRACS, MSE S. Waller PhD, MPhty; D. Nestel PhD, FAcadMed FSSH.

Correspondence to:

Dr Kathryn McLeod, Suite 1, Level 1, 83 Myers St Geelong VIC 3220, Australia.

dr.kat.mcleod@gmail.com, (03) 52298550. 
Funding: The corresponding author is a recipient of the Royal Australasian College of Surgeons 2019 Academy of Surgical Educators Surgical Education Research Scholarship.

Number of Figures and tables included:

Word count for abstract: 220

Word count for text (excluding abstract, acknowledgements, figure legends and references): 3531

Word count (abstract, table and references included) : 3999

\section{Abstract and keywords}

Background: Urological surgical trainees who underperform are difficult to identify, manage and, require significant resources in an already stretched system relying on pro bono supervisors that often have no formal training. Whilst there are commentaries on how to manage underperforming surgical trainees, there is a lack of data detailing the complex reasons for underperformance. It is important to understand the complexities contributing to underperformance so that improved remediation plans can be developed which can better help trainees meet expectations and succeed.

Methods: In this qualitative study, individual semi-structured interviews were conducted with key persons identified as having very high levels of background knowledge and involvement with current underperforming urological surgery trainees. Transcribed interviews were thematically analysed. 
Findings: Ten interviews were conducted, including nine urology consultants and one educational manager. Five themes were identified: underperformance is a small but profound issue; spiral of failure; the changing trainee; lack of insight and under supported supervisors and posts.

Discussion: Causes of underperformance in urology trainees are complex and multifactorial. Behavioural issues were considered the most likely cause, which are also the most challenging to remedy. However, in addition to trainee factors, causative factors related to supervision and training were identified. Addressing all of these issues is paramount if effective remediation of these trainees is to occur.

Key words: performance, causes, resident, surgery, specialist training, urology, qualitative research

\section{Main text}

\section{Introduction}

Identifying and managing trainees that underperform in urology is challenging. In addition to the personal impact on trainees, managing underperformance absorbs vast amounts of administrative and legal resources. Supervisors, who mostly work pro bono with little formal educational training, are often overwhelmed with the complexity of the issues, documentation and counselling involved. There are a variety of reasons for trainee underperformance and the root cause was not always clear(1). There is minimal published data on the reasons for underperformance in urology or on any Australasian surgical trainees.

Understanding the reasons behind underperformance is of utmost importance, so that trainees can be identified early and remediation strategies improved. 
Currently, urology trainees are formally assessed every three months according to the Royal Australasian College of Surgeons (RACS) competencies(2). The trainee is judged as satisfactory, borderline or unsatisfactory by their supervisor. Assessments are then discussed at the Regional Training Board meetings and ultimately if necessary at the Board of Urology meeting.

There is a paucity of published data on trainee underperformance. Data is not specific to surgical trainees, which have a distinct emphasis on technical skills which may not relevant to other specialities. Relevant publications mainly comprise commentaries on remediation and there are a small number of studies looking into causes of underperformance. While valuable, the commentaries are authored by a single expert(3),or comprise literature reviews(1), surveys(4) or quantitative data(5).

Rashid found that the cause is often with "non-technical skills" and that some trainees appear to be "immature in life skills and self-management"(6). Paice attributes trainee underperformance in the postgraduate setting to be related to: leadership; interpersonal conflict; delegating; dealing with complex scenarios and managing priorities(3). Another study identifies unprofessional behaviour with colleagues, insufficient medical knowledge, and poor clinical judgment(4). External causes include the work environment, educational framework and personal pressures on the trainee(3). Christensen described late and inconsistent feedback on inadequate performance and the perceived priority of efficient patient care before education as underlying causes (7). Not all of these reasons for underperformance are easily documented against the RACS competencies or on current assessment forms.

Surgical training relies heavily on an apprenticeship model. There is a close relationship between trainee and trainer (supervisor and other surgeons within the training unit), with the exchange of 
knowledge and skills integral to the learning process. Supervisors ultimately determine the assessment and progression of trainees. There are several theoretical frameworks that inform this study. We used situated learning theories(8) to explore learning experiences and the relationship between supervisor and trainee. We sought to understand the beliefs of senior educators and supervisors regarding underperformance of trainees.

\section{Methods}

\section{Approach}

A qualitative research approach was used since it is well suited to exploring complex issues. We adopted an interpretivist position acknowledging multiple realities. The COREQ checklist was used for reporting.

\section{Procedure}

Participants were recruited purposively inviting individuals with very high levels of knowledge, experience, responsibility and interaction with urology trainees in Australia and New Zealand (ANZ). These were current and past senior supervisors and office bearers, as well as education and training administrative staff at the USANZ. All participants had significant experience of dealing with current underperforming trainees at regional and national Board levels.

KM conducted ten semi-structured interviews (See Supplementary Appendix 1). While nine interviewees were practising consultant urological surgeons, one interviewee was an educational manager ( 8 male and 2 female). There was representation across ANZ. Participants chose to be interviewed either in person $(n=8)$ or Skype $(n=2)$. Interviews ranged from 22 to 56 minutes (mean 38). Participants appeared to speak freely about their experiences. Audio-recordings were transcribed professionally and checked for accuracy (KM). 
Thematic analysis described by Braun and Clarke(9) was used to analyse data. Three researchers (KM, SW, DN) independently open-coded three transcripts and then met to establish initial themes. These were then used to guide analysis of all transcripts (KM). Themes were further refined through research team discussion. The team comprised urological surgeons (KM, DK) involved in training and education; and educationalists (SW, DN) with no involvement in urology training. This composition enabled different perspectives to be brought to the analysis and aided reflexivity.

Ethical approval for this study was granted by Human Research Ethics Committee (University of Melbourne, Australia, ID 1852088.1).

\section{Results}

Interviewees described underperformance as being constructed on a continuum, with varying levels of concern. They also described it as a dynamic process which is continually affected by remediation and support processes. In its mildest form, underperformance is not uncommon or abnormal amongst trainees and usually rapidly rectified. When episodes of underperformance are repeated, it was considered that this cumulative effect had serious ramifications for the trainee.

Causes of underperformance are listed in Table 1 and the related themes are displayed in Table 2. Five themes and twenty subthemes were identified. The complexity of the causes of underperformance reflects the inevitable overlap in subthemes.

\section{Trainee underperformance - a small but profound issue.}

While most trainees are performing well, a small minority are underperforming and take up vast quantities of time, energy and resources. Interviewees mostly agreed that $5-10 \%$ of trainees would seriously underperform and obtain a borderline or unsatisfactory on their assessment at some point 
throughout their training. Key factors comprising serious underperformance included: repeated episodes of behaviours, failure to remediate, and consideration of dismissal.

All participants agreed that causes of serious underperformance are focused on deficiencies of "nontechnical" or behavioural skills, especially in the domain of professionalism. Other common domains included communication and collaboration. Deficiencies in multiple domains were cited as being common. Interviewees thought that although isolated underperformance in technical areas was possible, they were a rare cause and relatively easy to remediate with additional experience. Underlying issues contributing to technical deficiencies were considered to be behavioural in nature.

Remediation of behavioural issues in the long term was unlikely to be successful, although this rarely translated to dismissal due to issues with legal process. A point reiterated by interviewees was that each episode of underperformance is unique, which makes generic strategies for remediation unlikely to be successful.

Interviewees noted a change by the Board of Urology over time in managing underperformance, with a push towards transparency and accountability for graduating Fellows and ensuring standards of practice.

\section{Spiral of failure}

Interviewees cited that underperformance is usually a chronic issue. Underperformance issues revealed in later years were usually able to be traced back to trainees' junior years that were not rectified. Behavioural skill deficiencies take considerably longer to be acknowledged by the supervisor, compared with technical issues. Underperformance that it is ignored or excused in junior levels by supervisors also contributes to late identification. Underperformance that goes unmanaged or poorly 
managed, usually worsens with more responsibility as training continues and the level of expected independence rises. Underperformance acts in a downward spiral and compounding fashion.

The training calendar for urology trainees comprises 6-12 monthly rotations with quarterly formal assessments. The first two quarters are a time of learning and discovery, with the third quarter the usual term for identification of underperformance. However, this does not allow adequate time for successful remediation to occur prior to the start of the next clinical year in a different hospital and thus the spiral continues.

\section{Trainees - they are a changin'}

Interviewees spoke of "generational" differences between trainees and supervisors. They described how trainees have greater expectations in terms of education and training compared to past trainees. It was thought that they were less motivated to engage in "adult" learning practices. This is partly linked to the changing demographic of trainees with them being older, having family and more responsibility outside work. As a result, some were considered less focused on surgical training than previous cohorts. They reported that trainees were much more likely to access legal redress than in the past and demand evidence of any underperformance.

Interviewees also reported a significant proportion of trainees with performance issues experiencing and sharing additional stressors such as mental illness or family pressures. Some wondered whether the underperformance was the precipitant or reaction to the stressor.

\section{Lack of insight - it's like talking to a brick wall}

Interviewees thought lack of insight was a major issue in underperformance. Many underperforming trainees are blindsided by the feedback that they aren't meeting the expected standard. Interviewees 
thought that trainees who lack insight struggle to utilise feedback constructively. The lack of insight leads to an inability to reflect and enact meaningful change. When trainees are given feedback and specific examples of their underperformance, many become bogged down with providing an explanation of the circumstances or rationalisation of the concrete example rather than seeing it as an illustration of the bigger problem.

Often when behavioural skills are the cause of underperformance, any improvement after feedback was only temporary, reverting to baseline behaviours when stressors emerged. Successful remediation of lack of insight was thought to be extremely difficult as many believed this was related to inherent personality traits.

\section{It's not you, it's me - the under supported and underperforming supervisor and post}

All interviewees cited underperforming supervisors and training posts as having a significant impact on trainees. However, this is a difficult issue to address as supervisors work pro bono with little formal training and often little motivation to upskill. They are usually the newest consultants on the unit.

Supervisors are also not trained to deal with underperformance, and being a supervisor can be an onerous job. While supervisors are considered quite comfortable in identifying technical and knowledge-based deficiencies, they are usually out of their depth in relation to the identification, documentation and remediation of behavioural skills.

The culture in some hospital posts accepted a lack of supervision and teaching for the trainee, which may contribute to underperformance. In these posts, a trainee who asks for help or additional resources may be seen as underperforming. This can further potentiate a downward spiral in an already struggling trainee. The worst-case scenario in terms of performance is an underperforming trainee in an underperforming post. 
Many supervisors don't want to get involved in issues related to trainee underperformance due to a variety of factors. They may fail to fail the trainee, passing the problem onto the next unit due to: laziness (documentation and time requirements rise exponentially in an underperforming trainee), fear of being accused of bullying or anticipation of legal appeals.

\section{Discussion}

This study aimed to explore and deepen understanding of causes of trainee underperformance from the perspective of experienced supervisors. Causes of trainee underperformance are complex and multifactorial, which must be addressed when developing remediation programs. Behavioural issues which include lapses in professionalism are by far the most common cause of serious underperformance. This confirms findings from other studies (10). Unfortunately, they are also the most difficult aspects for supervisors to identify and remediate.

There are also other contributory factors outside a trainee's control. While easy to place blame with the trainee, some responsibility sits with supervisors and units, issues which are substantially more difficult to remediate than trainee issues. A holistic lens is needed which addresses trainee, supervisor and unit challenges. The sociocultural approach and remediation of workplace culture as suggested by Christensen(7) would be beneficial.

Participants discussed significant delays in the identification of underperforming trainees. Some of this was attributed to supervisors who do not have the skills to identify the underperforming trainee, but there was also the acknowledgement of 'failure to fail'. Described by Dudek(11), our data confirmed suggestions that this is caused by lack of documentation, lack of knowledge of what to document, anticipating an appeal process and lack of remediation options. Findings also suggest that 
supervisors may have other less honourable motivations such as laziness due to anticipation of consequent paperwork, counselling and remediation.

We need to set realistic trainee expectations and update training programs to adapt to the changing trainee. Supervisors should be selected for their skills and interest not because they are the most recent consultant to join the unit. Extra training in giving feedback and support for supervisors is required, especially those with underperforming trainees. Adjusting assessment reports so that they help supervisors identify and document underperformance that isn't easily mapped to the nine competencies would be helpful. Outdated posts that do not enable trainees to flourish should be remediated or abandoned.

It appears that some trainees are struggling with external stressors such as mental health. Most trainees do not want to inform supervisors of their stressors as they are perceived as weaknesses and they have the right to confidentiality. However, without supervisors and the Board knowing these circumstances, consideration cannot be given. Although units and supervisors should offer support to the trainee, 'fixing' these problems is not a supervisor or Board responsibility which adds complexity to this issue.

In this study, the community of practice (CoP) is comprised of consultant ("old timers") and trainee ("newcomer") urologists linked to a professional regulatory body (RACS and the Board of Urology) and health services in which patient care and training are located. While a CoP is characterised by its joint enterprise (delivering high quality urological patient care and surgical training), mutual engagement (provision of opportunities for supervision and training) and shared repertoire (the professional practices of urological surgeons)(12), it is clear that these characteristics are valued differently by members of the CoP. From our data, some supervisors simply do not have the resources to manage underperformance once identified; that some trainees do not have and perhaps will never have the personal resources (e.g. behavioural skills) to become full members of the CoP. This study 
has focused on the causes of underperformance of urology trainees. While underperformance sits with individual trainees, it is an issue for the entire CoP.

There was a significant amount of discussion by interviewees discussing their suggestions of potential solutions to the causes of underperformance. The major subthemes are included in Table 3.

The strengths of this study include that rich data was gathered from a targeted group using qualitative methods. This data would not have been obtained by auditing assessment forms from underperforming trainees. In addition, that the interviewer was a consultant surgeon aided in reflexivity and allowed for frank discussions with participants. Although this data is specific to urological trainees in Australia and New Zealand, results may have relevance in other surgical specialities due to similar training programs and trainee demographics.

Limitations of this study include the small number of study participants all of whom have had Board responsibilities. Because the interviewees had the highest level of knowledge and responsibility for trainee underperformance, we believe data sufficiency was achieved. The study participants were from a similar group of senior educators, so it is possible that this influenced the findings. However, multiple voices within this group were heard and documented systematically. Further research is needed to explore trainees' voices - those succeeding and those underperforming (although the latter come with significant ethical considerations). It is likely that the perspective from underperforming trainees themselves will differ significantly compared to the educationalist viewpoint.

\section{Conclusion}

The results of this qualitative study showed that underperformance is an uncommon but profound issue amongst urology trainees. The vast majority of underperformance is a deficiency in behavioural 
skills such as professionalism, communication and collaboration. Although technical skill deficiency is a rare cause of underperformance, it is relatively easy to rectify with additional experience as opposed to behavioural issues. Lack of insight was considered integral to behavioural issues and the difficulty in achieving long term remediation. The changing trainee, in terms of demographics and increased training expectations also contributes to a mismatch between actual and expected performance outcomes. In addition to trainee factors, underperforming and under supported supervisors and posts can also potentiate trainee underperformance by missing early opportunities to identify and remediate underperforming trainees. All of these aspects have to be considered when developing appropriate solutions for helping our struggling trainees improve in the workplace and emerge as better performing urologists.

\section{Acknowledgments}

This study was funded by the RACS, through an Academy of Surgical Educators Surgical Education Research Scholarship. We would like to thank the participants who were involved in the study.

\section{Disclosure statement}

KM reports a grant from the RACS, through an Academy of Surgical Educators Surgical Education Research Scholarship. DK, SW and DN declare no competing interests.

\section{References}

1. Rashid P, Grills R, Kuan M, Klein D. Trainee underperformance: a guide to achieving resolution. ANZ J Surg. 2015;85(5):303-7.

2. RACS. Competencies | Royal Australasian College of Surgeons 2015 [updated 23.01.2015. Available from: http://www.surgeons.org/becoming-a-surgeon/surgical-educationtraining/competencies/. 
3. Paice E. Identification and management of the underperforming surgical trainee. ANZ J Surg. 2009;79(3):180-4.

4. Bhatti N, Ahmed A, Stewart M, Miller R, Choi S. Remediation of Problematic Residents-A National Survey. The Layngoscope. 2016;126:834-8.

5. Guerrasio J, Garrity MJ, Aagaard EM. Learner deficits and academic outcomes of medical students, residents, fellows, and attending physicians referred to a remediation program, 20062012. Acad Med. 2014;89(2):352-8.

6. Rashid P. A qualitative perspectival review of the Australian and New Zealand Urology Education and Training program. BJU international. 2017;119(3):496-502.

7. Christensen MK, O'Neill L, Hansen DH, Norberg K, Mortensen LS, Charles P. Residents in difficulty: a mixed methods study on the prevalence, characteristics, and sociocultural challenges from the perspective of residency program directors. BMC Med Educ. 2016;16:69.

8. Brown JS, Collins A, Duguid P. Situated cognition and the culture of learning. Educational Researcher. 1989;18:32-42.

9. Clarke V, Braun V. Successful Qualitative Research- A practical Guide for Beginners. London: Sage; 2013.

10. Resnick A, Mullen J, Kaiser L, Morris J. Patterns and Predictions of Resident Misbehavior - a 10 year Retrospective Look. Current Surgery. 2006;63(6):418-25.

11. Dudek NL, Marks MB, Regehr G. Failure to Fail: The Perspectives of Clinical Supervisors. Academic Medicine. 2005;80(Supplement):S84-S7.

12. Wenger E, McDermott R, Synder W. Cultivating Communities of Practice. Boston, Massachusetts: Harvard Business School Press; 2002.

\section{List of supporting information}

a. COREQ (Consolidated criteria for reporting qualitative research)

b. List of Semi-structured interview questions 
Table 1: Identified causes of underperformance

4

5

6

7

8

11

12

Trainee Factors

- Unable to remediate due to lack of insight

- External factors/stressors

- Unrealistic expectations about educational program

- Unable to utilise constructive feedback

- Personality and behavioural/non-technical issues

- Technical issues - lack of motor dexterity

- $\quad$ Not well suited for career in surgery

Supervisor Factors

- Lack of timely and constructive feedback to trainee

- Inability to identify underperformance at early stages

- Ignoring underperforming behaviour

- Lack of formal training and experience in dealing with underperformance

Unit/Post Factors

- Lack of educational experience provided for trainee

- Unrealistic expectations of trainee ability 
Table 2: Descriptions of themes and subthemes with illustrative quotes

\begin{tabular}{|c|c|c|}
\hline Theme & Subtheme & Representative quotation \\
\hline A small but profound issue & $\begin{array}{l}\text { Repeated episodes of behavioural } \\
\text { issues are the predominant cause of } \\
\text { underperformance and difficult to } \\
\text { remediate. } \\
\text { Technical skills are a rare cause of } \\
\text { serious underperformance but easier } \\
\text { to remediate. } \\
\text { Root cause of most technical skill } \\
\text { deficiency is behavioural in nature. } \\
\text { Each underperformance is unique } \\
\text { which makes generic remediation } \\
\text { strategies difficult }\end{array}$ & $\begin{array}{l}\text { "I think universally they have some degree of issues with the non-technical skills ... so you are talking professionalism, } \\
\text { insight, judgement ... people who lack ...insight. . " - interview } 5 \\
\text { "There's perhaps maybe } 1 \% \text { of individuals who ... don't have the ability to ... be a technical operator ... visuospatial } \\
\text { orientation issues ... the vast majority ... can establish adequate technical and cognitive skills." - interview } 5 \\
\text { "[the Board] only really hear about the ones that are repeat offenders ... But they are the vast minority." - interview } 7\end{array}$ \\
\hline Spiral of failure & $\begin{array}{l}\text { Takes time for behavioural issues to } \\
\text { become apparent } \\
\text { Behavioural issues are chronic } \\
\text { Downward spiral with more } \\
\text { responsibility } \\
\text { Underperformance is identified and } \\
\text { acted upon too late }\end{array}$ & $\begin{array}{l}\text { "A lot of the time it doesn't get picked up at an early stage, .... lot of consultants ... they push them through because it's } \\
\text { easy to give them a tick and get them to the next job and let someone else deal with the problem," - interview } 4 \\
\text { "Old SET } 4 \text { (nSET 3) is ... the level where [underperformance] happens most commonly. Because they are gravitating to } \\
\text { that independent practice ....and they are starting to do the bigger stuff ... and that's when I think they struggle the most. " } \\
\text { - interview } 2\end{array}$ \\
\hline
\end{tabular}




\begin{tabular}{|c|c|c|}
\hline $\begin{array}{l}\text { Trainees, 'they are } \\
\text { a'changin' }\end{array}$ & $\begin{array}{l}\text { Generational change } \\
\text { Great expectations } \\
\text { Ease of legal access } \\
\text { External stressors on trainee }\end{array}$ & $\begin{array}{l}\text { " In the era of postgraduate medical degrees, we've got a large number of trainees that are actually in their } 30 \text { 's. Many of } \\
\text { them have partners, children, ... responsibilities. " - interview } 3 \\
\text { "You can call it a generational thing but I think trainees are less self-motivated, they're more inclined to be guided than } \\
\text { adult education self-directed learning." - interview } 5 \\
\text { "Trainees of today are ... are far more aware of their rights and being able to challenge and... appeal ... I think they are } \\
\text { very much more about "well where's the evidence?" - interview } 6\end{array}$ \\
\hline $\begin{array}{l}\text { Lack of insight: it's like } \\
\text { talking to a brick wall }\end{array}$ & $\begin{array}{l}\text { Blindsiding trainee } \\
\text { Unable to take feedback } \\
\text { Short improvement only } \\
\text { Personality issues and lack of insight } \\
\text { are near impossible to fix }\end{array}$ & $\begin{array}{l}\text { "These people are high performers, ... to be told that they are not that good comes as a shock to them ... and if it's lack of } \\
\text { insight [that's the] issue ... then it's natural for them to blame the person who is telling them." - interview } 2 \\
\text { "The lack of insight is that when say a specific example [is] given to a trainee ..., they don't ... reflect upon it and enact a } \\
\text { change. They tend to become defensive and ... justify ... that isolated incident. When in fact the incident is more } \\
\text { reflective of a pattern that needs changing." - interview } 10 \\
\text { "Some of the trainees have an ability to improve short-term ... if there's a challenge or a stress ... they slip back into the } \\
\text { same behaviours. "-interview } 6\end{array}$ \\
\hline $\begin{array}{l}\text { It's not you, it's me: } \\
\text { underperforming and } \\
\text { under supported } \\
\text { supervisors and posts }\end{array}$ & $\begin{array}{l}\text { Inadequate supervision can lead to } \\
\text { underperformance of trainees. } \\
\text { Managing underperformance is } \\
\text { effortful } \\
\text { Supervisors don't want to get involved } \\
\text { due to laziness and fear of being } \\
\text { accused of bullying } \\
\text { Lack of training in dealing with } \\
\text { underperformance and behavioural } \\
\text { issues }\end{array}$ & $\begin{array}{l}\text { "You see all too often that new junior consultants ...[is] the training supervisor. They've actually got no skill set to handle it } \\
\ldots . . \text { I don't think everyone can actually be a supervisor and we ... need to get better with who acts as supervisors." - } \\
\text { interview } 3 \\
\text { "A poorly performing post is pretty quick to point the finger at the trainee rather than ... self-reflect." - interview } 1 \\
\text { "People fail to fail. It's easier to ... slip them through." - interview } 8\end{array}$ \\
\hline
\end{tabular}


Table 3: Proposed solutions to underperformance

- Additional role modelling for trainees, especially those training in isolation.

- Adequate handover of trainees between supervisors

- More support for supervisors, especially those with underperforming trainees

- More recognition for supervisors

- Flexible and achievable upskilling for supervisors

- Greater use of mentors for trainees

- Early recognition of underperformance of trainees

- Additional support for trainees

- More frequent feedback to trainees

- Ability for trainees not suited to urology to change career paths without setbacks

- Improved selection process to avoid intake of trainees with personality issues. 


\section{List of supporting information}
a. COREQ (Consolidated criteria for reporting qualitative research)
b. List of Semi-structured interview questions 


\section{COREQ (Consolidated criteria for reporting qualitative research)}

\section{Domain 1: Research team and reflexivity}

Personal characteristics

1. Interviewer

KM conducted the interviews

2. Credentials

KM - MBBS, FRACS (Urol.), GradCert SurgEd

DK - MBBS, FRACS (Urol.), GradCert SurgEd

SW - PhD, MPhty

$\mathrm{DN}-\mathrm{PhD}$, FAcedMed, FSSH

3. Occupation

$\mathrm{KM}$ - urological surgeon

DK - urological surgeon

SW - physiotherapist and education researcher

DN - sociologist and education researcher

4. Gender

$\mathrm{KM}$ - female

$\mathrm{DK}$ - male

SW - female

$\mathrm{DN}$ - female

5. Experience and training

$\mathrm{KM}$ - Has had previous quantitative research experience. This study was undertaken as part of a MSurgEd supervised by DK, SW, DN. 
DK - previous experience in qualitative research.

SW - an experienced qualitative researcher in medical education.

$\mathrm{DN}$ - an experienced qualitative researcher in medical education.

Relationship with participants

6. Relationship established

$\mathrm{KM}$ is an early career consultant and was a known colleague to some of the participants. All participants were recruited as described below.

7. Participant knowledge of the interviewer

The reasons for completing the research were explicitly stated to participants in the consent form and research information sheet. Participants were aware that would be asked their opinions about causes of trainee underperformance. Participants were aware that the interviewer was a consultant surgeon.

8. Interviewer characteristics

KM's role as a supervisor and surgeon had the advantage that familiarity with the topic helped her understand participants language and terminology, and ask exploratory questions. Recognising that this could also be a potential disadvantage through influencing participants responses and her interpretation, SW and DN added a non-surgical stance.

\section{Domain 2: Study Design}

Theoretical framework

9. Methodological orientation and Theory 
The study is aligned with the ontological position of interpretivism in which meaning is drawn from the subjective experiences of individuals engaging in social interaction and attempts to make sense of what is perceived as reality. The epistemological stance is consistent with a constructivist view of knowledge.

\section{Participant selection}

10. Sampling

Purposive sampling was used.

\section{Method of approach}

The individuals chosen were focused on the Board of Urology and Chairs of the Training Committee in each region. All of these individuals are current Urological Surgeons working in the public health system in Australia and New Zealand. These individuals have been identified as they have the highest level of background knowledge and participation with current underperforming trainees across the entire cohort across Australia and New Zealand. Individuals were approached by email by student researcher Dr McLeod and invited for an individual interview. The identity of these individuals is publicly available via the USANZ website $<$ https://www.usanz.org.au/board-of-urology21/>. Participation was voluntary.

12. Sample size

Ten participants were interviewed.

13. Non-participation

No potential interview candidates declined to participate.

Setting

14. Setting of data collection 
Participants were interviewed in person at a private location or via Skype interview. Eight participants were interviewed in person, and two participants had Skype interview. The reason for the Skype interviews was convenience due to location.

15. Presence of non-participants

Only the participant and interviewer were present.

16. Description of sample

All Australian state and territories, and New Zealand were represented amongst the interviewed participants. All participants were highly knowledgeable and experienced in the topic area.

\section{Data Collection}

17. Interview guide

A semi-structured interview framework was used (Appendix 1). It was pilot tested.

18. Repeat interviews

Repeat interviews were not required.

19. Audio recordings

Interviews were audiotaped digitally and transcribed by a medical typist.

20. Field notes

Field notes were made during and after each interview and kept as part of a diary.

21. Duration

The interviews ranged in total length from 35 minutes to almost 60 minutes.

22. Data saturation

The contested notion of data saturation is not appropriate for this study. In regard to data sufficiency because the interviewees had the highest level of knowledge and 
responsibility in regard to trainee underperformance, we believe our data and subsequent findings are sufficient to make these claims.

23. Transcripts returned Transcripts were offered to all participants for checking. No participants elected to review their transcripts.

\section{Domain 3: analysis and findings}

Data analysis

24. Number of data coders

The first interview was coded independently by KM and DN. The interviews 2-4 were coded independently by KM, DN and SW. The remaining six were coded by KM.

25. Description of the coding tree

Coding was performed manually. A 'mind map' was used instead of a coding tree in order (available from authors on request) as there was considerable fluidity between the themes and subthemes.

26. Derivation of themes

Themes were derived from the data.

27. Software

Software was not used.

28. Participant checking

Transcripts were offered to all participants for checking. No participants elected to review their transcripts or become in involved in data analysis.

\section{Reporting}


29. Quotations presented

Participant quotations are presented in Table 1. Each is identified by participant number.

30. Data and findings consistency

There was good consistency between data and findings.

31. And 32. Clarity of major and minor themes

Major themes and minor themes are presented in the findings. However, the similarity of experiences between participants was striking, as was the overall lack of divergent experiences. Divergent opinions have been discussed in findings.

\section{Reference:}

Tong A, Sainsbury P, Craig J. Consolidated criteria for reporting qualitative research (COREQ): a 32-item check list for interviews and focus groups. Int J Qual Health Care 2007; 19, 349-357. doi:10.1093/intqhc/mzm042 


\section{List of Semi-structured interview questions}

1. What has been your experience to date with trainees, and in particular in regard to underperforming trainees?

2. How common are underperforming trainees?

3. How have issues of underperformance evolved over your time supervising trainees?"

4. What are the implications of underperforming trainees at micro/macro/meso levels?

5. In your opinion, what are the main reasons for underperformance in trainees?

6. Which reasons for underperformance are more difficult to manage than others?

7. How do we currently manage underperforming trainees?

8. What are the limitations and difficulties in managing these trainees?

9. How do you think we could improve the management of underperforming trainees?

10. Are there any barriers to enacting these changes? 


\section{University Library}

\section{- M M I N E R VA A gateway to Melbourne's research publications}

Minerva Access is the Institutional Repository of The University of Melbourne

Author/s:

McLeod, K;Waller, S;King, D;Nestel, D

Title:

Struggling urology trainee: a qualitative study into causes of underperformance

Date:

2020-06-01

Citation:

McLeod, K., Waller, S., King, D. \& Nestel, D. (2020). Struggling urology trainee: a qualitative study into causes of underperformance. ANZ JOURNAL OF SURGERY, 90 (6), pp.991-996. https://doi.org/10.1111/ans. 15825.

Persistent Link:

http://hdl.handle.net/11343/275546 